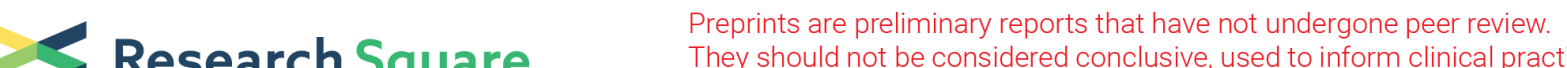 $\begin{array}{ll}\text { Research Square } & \text { They should not be considered conclusive, used to inform clinical practice, } \\ \text { or referenced by the media as validated information. }\end{array}$
}

\section{Transcriptome Analysis of Related-genes to MeJA Treatment Metabolite Synthesis in Hairy Roots of Broccoli (Brassica oleracea L. var. Italic Planch)}

jinyu Bao ( $\sim 1031817055 @ q q . c o m)$

Gansu Agricultural University https://orcid.org/0000-0002-5777-7334

Xu Lu

Gansu Agricultural University

Lei Ma

Gansu Agricultural University

Xiumin Zhang

Gansu Agricultural University

Peng Tian

Gansu Agricultural University

Xiaoling Zhang

Gansu Agricultural University

Sheng Li

Gansu Agricultural University https://orcid.org/0000-0003-0432-9578

Shaoying Ma

Gansu Agricultural University

Jie Yang

Gansu Agricultural University

Yaqi Lu

Gansu Agricultural University

Yunchun Wei

Gansu Agricultural University

Congcong Zhang

Gansu Agricultural University

\section{Research Article}

Keywords: Methyl jasmonate, Broccoli hairy roots, Transcriptomics, Glucoraphanin, Sulforaphane

Posted Date: August 17th, 2021

DOl: https://doi.org/10.21203/rs.3.rs-585399/v1 
License: (c) (i) This work is licensed under a Creative Commons Attribution 4.0 International License. Read Full License 


\section{Abstract}

Hairy roots obtained by infecting broccoli (Brassica oleracea L. var. Italic Planch) leaves with Agrobacterium rhizogenes (ATCC15834) had the characteristics of phytohormone autonomy, genetic stability and can produce a large amount of anti-cancer substance Sulforaphane (SF) and SF biosynthetic precursors substance Glucoraphanin (GRA). The production of SF in hairy roots of broccoli increased significantly under the induction of exogenous signal molecule Methyl jasmonate (MeJA). However, the molecular mechanism of MeJA treatment hairy roots of broccoli have not been reported. In this study, the optimal concentration of MeJA for having treatment broccoli hairy roots were selected based on the yield of GRA and SF. After grew 18 days, broccoli hairy roots were treated with $10 \mathrm{mmol} / \mathrm{L}$ MeJA for $0,3,6,9$ and $12 \mathrm{~h}$ respectively. Compared with $0 \mathrm{~h}$, the yields of GRA and SF increased under other treatments. The highest yield of GRA and SF was noted at $9 \mathrm{~h}$, which were 2.22 -fold and 1.74 -fold of $0 \mathrm{~h}$, respectively. Broccoli (Brassica oleracea $\mathrm{L}$. var. botrytis $\mathrm{L}$ ) as reference genome, and $1195 \mathrm{co-}$ differentially expressed genes (DEGs) at $0,3,6,9$ and $12 \mathrm{~h}$ was observed under treatment $10 \mathrm{mmol} / \mathrm{L}$ MeJA, which there were 3,826 down-regulated and 574 up-regulated genes. The six key genes that regulated Glucosinolates (GLS) synthesis, MAM1, CYP79B1, CYP83B1, UGT74B1, and FMOGS-OX5, were up-regulated at 0 and $3 \mathrm{~h}$, and down-regulated at the rest of the time; $B C A T 2$ was up-regulated at $6,9,12$ $\mathrm{h}$, and at 0, $3 \mathrm{~h}$ expression was down-regulated, transcription factors MYB34 and MYB122 were upregulated at $3 \mathrm{~h}$, and down-regulated at other time points, MYB51 was up-regulated at 0, $3 \mathrm{~h}$ and downregulated at 6,9,12 h. The pathway diagram of GRA biosynthesis and transformation pathway in broccoli hairy roots treatment by MeJA simulated, and the molecular mechanisOm of GRA biosynthesis and SF accumulation in broccoli hairy roots under MeJA treatment were revealed.

\section{Introduction}

For Brassica plants, Methyl jasmonate (MeJA) as an inducer can promote the biosynthesis of Glucosinolates (GLS) (Kim et al., 2017). GLS was divided into three categories: aliphatic GLS from methionine, isoleucine, leucine or valine; aromatic GLS from tyrosine or phenylalanine; and indole GLS from tryptophan Family (Vo et al., 2018; Zhao et al., 2017; Zhang et al., 2015; Miao et al., 2016). With further study of GLS, the key steps of the GLS biosynthetic pathway have been confirmed, mainly including three stages: the extension of the amino acid side chain, the formation of the GLS core structure, and the secondary side-chain modifications (SanchezPujante., 2017). The biosynthesis and degradation of GLS are regulated by a series of genes (Aghajanzadeh et al., 2018). Aliphatic GLS biosynthesis is regulated by CYP79F1 / CYP79F2, CYP83A1, SUR1, UGT74B1 and SOT18 (Banerjee et al., 2016). Glucoraphanin (GRA), a kind of aliphatic GLS is the focus in this study. GRA does not have biological activity. It could be hydrolyzed by Myrosinase (MYR) to form various products, including Isothiocyanates (ITC), thiocyanates, nitriles (Tang et al., 2013). Sulforaphane (SF) is one of ITCs. As a food-borne metabolite, SF is one of the strongest anti-cancer natural active ingredients known to date in vegetables (Klaus et al., 2011). It has been shown SF play a key role in preventing cardiovascular disease (Traka et al., 2016), antibacterial and anti-inflammatory (Choi et al., 2014), and antioxidant (Kang et al., 
2017). At present, SF is mainly obtained from broccoli seeds or seedlings, which have the problems of low yield and high cost. Thus, finding the appropriate approach to increasing SF is of great importance due its role in preventing cancer and some diseases.

It is reported that hairy roots were a good source of metabolites such as indigotin production in Isatis tinctoria L (Jiao et al., 2018), solasodine production in Solanum trilobatum L. (Shilpha et al., 2015), tanshinone production in Salvia miltiorrhiza (Wang et al., 2013), which indicated that hairy root culture may solve the problem of low SF synthesis capacity. The broccoli hairy root culture system has been successfully established in a previous study (Zhao., 2015). SF in leaves, young roots of broccoli aseptic seedlings and Hairy roots were detected by HPLC, and SF content in hairy roots was 13.07 and 31.28-fold of that in leaves and young roots respectively $(\mathrm{Hu}, 2016)$. Therefore, broccoli hairy roots have certain advantages over other Brassica plants for obtaining more SF production. Studies on GLS biosynthesis and regulation of broccoli seedlings treated with MeJA have been reported (Yu et al., 2018). But it has not been reported about related genes expression of GRA and SF synthesis in broccoli hairy roots.

In this study, different concentrations of MeJA were utilized to treat broccoli hairy roots, and broccoli hairy roots were treated at the optimal concentration selected. Using Illumina sequencing technology, broccoli (Brassica oleracea L. var. botrytis $\mathrm{L}$ ) was used as a reference genome to explore. The molecular mechanism of GRA biosynthesis in hairy roots of broccoli treatment by exogenous signal molecule MeJA at different times aims to provide explanation for the gene regulation mechanism of GRA and SF anabolic pathways in hairy roots of broccoli.

\section{Materials And Methods}

\subsection{Plant material}

Referred to the broccoli hairy root culture system established in our laboratory (Zhang et al., 2020), Collected the leaves of broccoli sterile seedlings, took the $0.5 \mathrm{~cm}^{2}$ size of broccoli sterile seedling leaves as explants, put them on solid MS medium, incubated at $25^{\circ} \mathrm{C}$ for 4 days in the dark, and used activated Ag.rhizogenes ATCC15834 after the cultivation Ag.rhizogenes (with an OD600 value of 0.4-0.5) was used for infection. The container was shaken during the infection ( $5 \mathrm{~min}$ ), and then transferred to an induction medium (MS $+100 \mu \mathrm{mol} / \mathrm{L}$ acetosyringone), followed by dark culture at $25^{\circ} \mathrm{C}$; The co-cultivated leaves were transferred to a sterilization medium (MS $+250 \mathrm{mg} / \mathrm{L}$ carbenicillin disodium), and cultured in the dark at $25^{\circ} \mathrm{C}$, sterilized once a week, and sterilized completely after 2 subcultures. In the super clean bench, the hairy roots of broccoli were inoculated with $1 \mathrm{mg} / \mathrm{mL}$ inoculation amount in $100 \mathrm{~mL} \mathrm{MS}$ medium and were cultured at $25^{\circ} \mathrm{C}$ and $110 \mathrm{r} / \mathrm{min}$ rotation speed in darkness. (Fig. 9)

\subsection{Identification of hairy roots}

Search on NCBI (https://www.ncbi.nlm.nih.gov/genbank/) to find the sequence of candidate genes and use Primer 5.0 software to design primers, The primers for rolC gene were designed as: 5'-

GCGACGTATCGTCCAGCGAT-3'®' $5^{\prime}$-GCCATGCCTCACCAACGC-3'. Total RNA extraction from plants using an 
DNA kit (Tiangen DP305-02). Plasmid DNA extraction using an DNA kit (Tiangen DP103-02). The PCR amplification $(20 \mu \mathrm{L})$ mixture included $1.5 \mu \mathrm{L}$ template DNA, $3 \mu \mathrm{L}$ of each primer, $15 \mu \mathrm{L}$ Taq DNApolymerase, $5.5 \mu \mathrm{L} \mathrm{ddH_{2 }}$ O. The thermal cycling program consisted of an initial denaturing step of $93^{\circ} \mathrm{C}$ for $5 \mathrm{~min}$, denaturation of $93^{\circ} \mathrm{C}$ for $40 \mathrm{~s}$, annealing of $60-65^{\circ} \mathrm{C}$ for $40 \mathrm{~s}$, elongation of $72^{\circ} \mathrm{C}$ for $45 \mathrm{~s} ; 35$ cycles, elongation step of $72^{\circ} \mathrm{C}$ for $10 \mathrm{~min}$. The PCR products were separated by electrophoresis in a $0.6 \%$ agarose gel electrophoresis with $0.01 \%$ ethidium bromide in $1 \mathrm{X}$ TAE buffer. Electrophoresis conditions: voltage $140 \mathrm{~V}$, current $100 \mathrm{~mA}, 30 \mathrm{~min}$. The results were observed by gel imaging system (BIO-RAD Gel ${ }^{\mathrm{TM}}$ Doc XR+). (Fig. 10)

\subsection{Treatment of methyl jasmonate \\ 2.3.1 Preparation of methyl jasmonate}

Prepared $5 \mathrm{~mol} / \mathrm{L}$ MeJA solution was finished in an ultra-clean work bench: firstly, accurately measuring $20.630 \mathrm{~mL}$ of MeJA stock solution, added $60^{\circ} \mathrm{C}$ ethanol with a volume ratio of $1: 2$, finally distilled water was added until the volume was $30 \mathrm{~mL}$. After MeJA solution was filtered by $0.22 \mu \mathrm{m}$ filter membrane, it was poured into a sterilized $10 \mathrm{~mL}$ centrifuge tube, stored at $4^{\circ} \mathrm{C}$, heated the MeJA solution under $90^{\circ} \mathrm{C}$ in a water bath before using. MeJA was purchased from sigma company in the United States with a purity of $99 \%$ and CAS number 39924-52-2.

\subsubsection{Screened of optimal concentration of methyl jasmonate}

According to the previous research, the growth stages of broccoli hairy roots be divided into five periods: retarded period $(0 \sim 3 \mathrm{~d})$, differentiation period $(3 \sim 9 \mathrm{~d})$, proliferation period $(9 \sim 18 \mathrm{~d})$, stable period (18 $21 \mathrm{~d}$ ) and decline period (after $21 \mathrm{~d}$ ) (Zhang et al., 2020). Studies have shown that metabolite synthesis was in the late stage of plant proliferation (Siwach et al., 2013). According to our previous research, at 18th d broccoli hairy roots was at the late stage of proliferation and GRA and SF could be rapidly synthesized (Zhang, 2020). Therefore, the hairy roots were treated with MeJA elicitors on the 18th day to bring the concentration of MeJA in the liquid medium to $0,1,5,10$, and $15 \mathrm{mmol} / \mathrm{L}$, and was harvested after $12 \mathrm{~h}$, repeated 3 times each group experiment. The production of GRA and SF were measured in culture system under different treatment.

\subsubsection{Processing of transcriptome samples MeJA}

Broccoli hairy roots grown 18th d was treated with $10 \mathrm{mmol} / \mathrm{L} \mathrm{MeJA}$, and was respectively harvested for $0,3,6,9$ and $12 \mathrm{~h}$, repeated each group of experiments 3 times, and took an appropriate amount of each sample to determine its GRA and SF yield. In this study, transcriptome analysis was performed at five time points: $0,3,6,9$ and $12 \mathrm{~h}$.

\subsection{HPLC Analysis of glucoraphanin \\ 2.4.1 Extraction of glucoraphanin}


Referred to the method of (Zhang et al., 2020) with slight modifications and improvements. Collected 0.3 $\mathrm{g}$ of material, added $6 \mathrm{~mL}$ of $80 \%$ ethanol with the ratio of material to liquid $1: 20(\mathrm{~g} / \mathrm{ml})$, water bath at $80^{\circ} \mathrm{C}$ for $20 \mathrm{~min}$, grounded the material into paste, added $3 \mathrm{~mL}$ of $80 \%$ ethanol by the ratio of $1: 10(\mathrm{~g} / \mathrm{ml})$, water bathed at $80^{\circ} \mathrm{C}$ for $20 \mathrm{~min}$, treatmented ultrasonic for $15 \mathrm{~min}$, filtered and collected the filtrate, repeated twice, combined the filtrate and evaporate total filtrate to paste at $55^{\circ} \mathrm{C}$. Finally, diluted the eluate to $9 \mathrm{~mL}$, after $0.22 \mu \mathrm{m}$ filter membrane, and determined the concentration by HPLC.

Accurately measured $10 \mathrm{~mL}$ MS liquid medium, and concentrated by vacuum at $60^{\circ} \mathrm{C}$. After evaporation, eluted with an appropriate amount of chromatographic methanol, and cleaned by ultrasonic cleaning machine cleaning. Finally, diluted the eluate to $9 \mathrm{~mL}$, after filtered with $0.22 \mu \mathrm{m}$ membrane, and determined the concentration by HPLC.

\subsubsection{Detection Conditions of glucoraphanin by HPLC}

Shimadzu high performance liquid chromatography (CTO-15C) was used to detect glucoraphanin, Elite Hypersil BDS C18 $(250 \times 4.6 \mathrm{~mm}, 5 \mu \mathrm{m})$ chromatographic column; mobile phase was methanol: water = 4:96 (V/V); flow rate: $0.8 \mathrm{~mL} / \mathrm{min}$; column temperature: $35^{\circ} \mathrm{C}$; detection wavelength: $226 \mathrm{~nm}$; injection volume: $20 \mu \mathrm{L}$. The measured peak area was substituted into the regression equation $\mathrm{Y}=5,975.6 \mathrm{X}-$ $6,995.9, R^{2}=0.999, Y$ was the peak area, $X$ was the glucoraphanin concentration, and the glucoraphanin concentration was calculated.

\subsection{HPLC Analysis of sulforaphane}

\subsubsection{Extraction of sulforaphane}

Referred to (Zhang et al., 2020) method and modify it slightly. First, a mustard enzyme solution was prepared: Yellow mustard (Semen Sinapis) was crushed and sieved. Weighed $5 \mathrm{~g}$ of mustard powder and added $100 \mathrm{~mL}$ of distilled water at 1:20 (g/mL). After ultrasonic vibrated at $25^{\circ} \mathrm{C}$ for $30 \mathrm{~min}$, the curded mustard enzyme solution was removed by suction filtration, and mustard enzyme activity measured was $0.7 \mathrm{U} / \mathrm{g}$ DW. Enzyme treatment: Collected $5 \mathrm{~g}$ in 3.1 preparation material and added $20 \mathrm{~mL}$ mustard enzyme solution (with the same volume of distilled water as a control) at a material-liquid ratio of 1:4 $(\mathrm{g} / \mathrm{mL})$, and added $100 \mathrm{~mL}$ of $95 \%$ ethanol at $1: 20(\mathrm{~g} / \mathrm{mL})$, then water bath at $37^{\circ} \mathrm{C}$ for $60 \mathrm{~min}$ and sonic for $30 \mathrm{~min}$, collected the filtrate after filtration, rotate at $65^{\circ} \mathrm{C}$ until the liquid was completely evaporated to dryness, rinsed the distillation flask with $10 \mathrm{~mL}$ of distilled water, added $30 \mathrm{~mL}$ of ethyl acetate at a ratio of $1: 2(\mathrm{~mL} / \mathrm{mL})$ repeated extraction for 3 times. Combined ethyl acetate phases solution at $55^{\circ} \mathrm{C}$ and spanned the solution to a pasted at $55^{\circ} \mathrm{C}$, the paste was dissolved with chromatographic methanol and made up to $9 \mathrm{~mL}$, after filtered with $0.22 \mu \mathrm{m}$ filter membrane, and SF amount was determined by HPLC.

Referred to (Zhang et al., 2020) method and modified slightly. Accurately measured the volume of the MS medium, added ethyl acetate by volume ratio of the medium to ethyl acetate $1: 2(\mathrm{~mL} / \mathrm{mL})$ and repeated extraction 3 times. The ethyl acetate phase collected was concentrated by rotary evaporator at $60^{\circ} \mathrm{C}$ until the solution was completely evaporated, used an appropriate amount of chromatographic methanol to 
elute, and cleaned with ultrasonic cleaning instrument. Finally, made up the eluent to $9 \mathrm{~mL}$, filtered with $0.22 \mu \mathrm{m}$ filter membrane, and SF amount was determined by HPLC.

\subsubsection{Detection Conditions of sulforaphane by HPLC}

Shimadzu high performance liquid chromatography (CTO-15C) was used to detect sulforaphane. Shimadzu WondaSil C18 $(150 \times 4.6 \mathrm{~mm}, 5 \mu \mathrm{m})$ chromatographic column. The organic phase and the water phase were respectively chromatographic methanol and ultrapure water. Binary high-pressure elution procedure: 0.01 min 35\% methanol, 12 min 35\% methanol, 20 min 100\% methanol, 25 min $35 \%$ methanol; flow rate: $0.8 \mathrm{~mL} / \mathrm{min}$; column temperature: $35^{\circ} \mathrm{C}$; detection wavelength: $201 \mathrm{~nm}$; injection volume: $20 \mu \mathrm{L}$. The measured peak area was substituted into the regression equation $Y=3 \times 10^{-5} X$ $0.5104, R^{2}=0.999, X$ was the peak area, $Y$ was the sulforaphane concentration, and the sulforaphane concentration was calculated.

Noted: in this experiment, the inoculation amount of hairy root was $1 \mathrm{mg} / \mathrm{mL}$ and the bottling amount of liquid medium was $100 \mathrm{~mL}$, and broccoli hairy root was treated with MeJA under different conditions. Finally, the yield of each bottle of hairy root and SF in the medium was calculated, using the unit of g/flask

\subsection{RNA extraction library construction and sequencing}

Total RNA was obtained using a quick RNA Isolation Kit (Huang yueyang, Beijing, China) according to the manufacturer's instructions, and contaminant DNA was removed. The concentration and quality of the RNA were verified using an Agilent 2100 Bioanalyzer (Agilent Technologies, Palo Alto, CA, USA). After total RNA was extracted, eukaryotic mRNA was enriched by Oligo(dT) beads, while prokaryotic mRNA was enriched by removed rRNA by Ribo-Zero ${ }^{\mathrm{TM}}$ Magnetic Kit (Epicentre). Then enriched mRNA was fragmented into short fragments using fragmentation buffer and reverse transcript into cDNA with random primers. Second-strand cDNA were synthesized by DNA polymerase I, RNase H, dNTP and buffer. Then the cDNA fragments were purified with QIAquick PCR extraction kit, end repaired, poly(A) added, and ligated to Illumina sequencing adapters. The size of ligation products was selected by agarose gel electrophoresis, PCR amplified, and sequenced using Illumina HiseqTM 2500 by Gene Denovo Biotechnology Co. (Guangzhou, China).

\subsection{Filtering of Clean Reads}

Reads obtained from the sequencing machines include draw reads containing adapters or low-quality bases which would affect the following assembly and analysis. Thus, reads would be further filtered to obtain high quality clean reads according to the following rules:

1) Removed reads containing adapters;

2) Removed reads containing more than $10 \%$ of unknown nucleotides $(\mathrm{N})$;

3) Removed low quality reads containing more than $50 \%$ of low quality (Q-value $\leq 20)$ bases. 


\subsection{Alignment with Ribosome RNA (rRNA)}

Short reads alignment tool Bowtie2(Langmead et al., 2012) was used for mapping reads to ribosome RNA (rRNA) database. The rRNA mapped reads would be removed. The remaining reads were further used in assembly and analysis of transcriptome.

\subsection{Alignment with Reference Genome}

The rRNA removed reads of each sample were mapped to reference genome by TopHat2(Kim et al., 2013) (version 2.0.3.12), respectively. The alignment parameters were following:

1) Maximum read mismatch was 2

2) The distance between mate-pair reads was $50 \mathrm{bp}$

3) The error of distance between mate-pair reads was $\pm 80 \mathrm{bp}$

After aligned with reference genome, unmapped reads (or mapped very poorly) were then re-aligned with Bowtie2, the enriched unmapped reads were split into smaller segments which were then used to find potential splice sites. The section and the section position of these short segments were predicted as well. A set of splice sites were built with initial unmapped reads by TopHat2 without relying on the known gene annotation (Trapnell et al., 2010). Not only be used for identifying expressed genes and their quantitative expression, the sequence alignment would also be helpful to find alternative splicing and new transcripts.

\subsection{Transcripts Reconstruction}

The reconstruction of transcripts was carried out with software Cufflinks (Trapnell et al., 2012), which together with TopHat2, allow biologists to identify new genes and new splice variants of known ones. The program reference annotation-based transcripts (RABT) were preferred. According to reference, Cufflinks constructed faux reads made up for the influence of low coverage sequencing. During the last step of assembly, all of the reassembles fragments were aligned with reference genes and then similar fragments were removed. Cuffmergetomerge transcripts from different replicas of a group are consolidated into a comprehensive set of transcripts, and then merged the transcripts from multiple groups into a finally comprehensive set of transcripts for further downstream differential expression analysis.

\subsection{Differentially expressed genes (DEGs) Analysis}

To identify differentially expressed genes across samples or groups, the edgeR package (http://www.rproject.org/ ) was used. The results identified genes with a fold change $\geq 2$ and a false discovery rate $(F D R)<0.05$ in a comparison as significant DEGs. DEGs were then subjected to enrichment analysis by 
GO (http://www.geneontology.org/)functions and KEGG pathways.KEGG was the major public pathwayrelated database(Minorw et al., 2008).

\subsection{Quantitative Real-Time PCR (qRT-PCR) Analyswas}

Search on NCBI (https://www.ncbi.nlm.nih.gov/genbank/) to find the sequence of candidate genes and use Primer 5.0 software to design primers,primer sequences shown(Table 1). Total RNA was isolated using an RNA kit (Tiangen DP 432). CDNA synthesis and qRT-PCR analysis were performed using a onestep SYBR Prime script plus RT-PCR kit (Tiangen FP 209). According to the following scheme, PCR amplification was performed in a 96-well platform (Roche LC96 in the Switzerland): $180 \mathrm{~s}$ at $95^{\circ} \mathrm{C}, 5 \mathrm{~s}$ at $95^{\circ} \mathrm{C} ; 15 \mathrm{~s}$ at $60^{\circ} \mathrm{C}, 40$ Times. The melting curve analysis was performed at $60^{\circ} \mathrm{C} \sim 95^{\circ} \mathrm{C}$. Total RNA concentration and gel electrophoresis were used to remove genomic DNA and reverse transcription. According to the $\mathrm{Ct}$ value of the target gene and the internal reference gene, the gene expression level was calculated by the $2^{-\Delta \Delta C t}$ method (Livak method).

\subsection{Data analysis}

The experimental data are statistically analysis using SPSS 21.0 software, and the significance of the difference is tested using Duncan's new complex range method $(P \leq 0.05)$. The data are processed and pictures and tables are made by Excel 2018 and Origin 2018, and pictures were edited with Photoshop 2018.

\section{Results And Discussion}

\subsection{Effect of MeJA on the production of GRA and SF in broccoli hairy roots cultural system}

Hairy roots of broccoli were treated with $0,1,5,10$, and $15 \mathrm{mmol} / \mathrm{L} \mathrm{MeJA}$ for $12 \mathrm{~h}$, The results shown that under the concentration of $10 \mathrm{mmol} / \mathrm{L}$ MeJA, the total yields of GRA and SF were $5049.27 \mu \mathrm{g} /$ flask and $2549.34 \mu \mathrm{g} /$ flask, respectively, which were 2.79 and 2.22-fold of the control(Fig. 1-A. B). Under the induction of $10 \mathrm{mmol} / \mathrm{L} \mathrm{MeJA}$ concentration, the total yields of hairy roots GRA and SF reached the maximum.

Summed up the above the optimal concentration of MeJA was selected to be $10 \mathrm{mmol} / \mathrm{L}$. On the basis, was added to the hairy roots of broccoli grown $18 \mathrm{~d}$ was treated with MeJA a concentration of 10 $\mathrm{mmol} / \mathrm{L}$ treatment $0,3,6,9$, and $12 \mathrm{~h}$, and 0 -hour treatment was used as a control. As shown in Fig. 2, the yields of GRA and SF firstly increased then decreased between 3 to $12 \mathrm{~h}$. The yield of GRA and SF reached the highest in $9 \mathrm{~h}$, which were 2.27 -fold and 1.74 -fold of $0 \mathrm{~h}$, respectively. Therefore, it can be preliminarily concluded that the yield of GRA and SF in broccoli hairy roots treated with $10 \mathrm{mmol} / \mathrm{L} \mathrm{MeJA}$ 
reached the maximum at $9 \mathrm{~h}$. At the same time, GRA yield in hairy roots was significantly higher than in medium, while SF yield in medium was significantly higher than in hairy roots (Fig. 2-A.B).

MeJA treatment of plants can stimulate the defense response mechanism in plants, thus affected the synthesis and metabolism of plant metabolites (Baenas et al., 2014). Zang et al (2015) found that treatment MeJA significantly increased the GLS content in hairy roots of turnips. In this study, when MeJA concentration reached $10 \mathrm{mmol} / \mathrm{L}$, the production of GRA and SF in hairy roots reached the maximum. The yields of GRA in medium were lower than that in hairy roots under treatment with MeJA, but the yields of SF in medium were $10 \sim 100$-fold of that in hairy roots. There was a difference in the yields of GRA and SF in the suspension culture system of hairy roots in the liquid medium. The reason may be that GRA exists in the vacuole of cells, and SF was produced after the vacuole was broken and contacted with MYR (Makoto et al., 2017). SF was easier to release to medium than GRA with vacuolar protection under the action of shear force generated by the rotation speed of the incubator shaker. Cacao et al (2012) reported that added MeJA to the suspension culture system of silymarin, which increased the amount of silymarin in the liquid medium by 2 -fold. It was suggested that MeJA could increase the released number of metabolites to the medium. Probably because the induction of jasmonates makes the plant cell membrane extremely vulnerable to stress (Luo et al., 2010), which affects the permeability of the cell membrane and releases metabolites into the culture medium. The release mechanism of GRA and SF in hairy roots of broccoli treatment by MeJA was yet to be further studied.

\subsection{MeJA treatment RNA sequencing of broccoli hairy root transcriptome}

Based on the transcriptome sequencing results, 9 samples were selected for this study, and each sample produced approximately 4,214,000 to 6,308,800 paired end reads (Table 2). The GC content of the 9 library sequence data was between $47.47 \sim 48.12 \%$, and the Q30\% value (average mass fraction > 30) was $95 \%$, Sequence read rates were all above $90 \%$. The results showed that the quality and accuracy of the sequencing data could be analyzed in the next step.

\subsection{Identification of differential expression genes (DEGs) in broccoli hairy roots treatment by MeJA}

MeJA-treatment differentially expressed genes of hairy roots of broccoli were identified from the Illumina transcriptome. Broccoli hairy roots were treatment by MeJA for 0, 3 and $9 \mathrm{~h}$. Compared $0 \mathrm{~h}$ sample with 3 h sample, a total of 5,757 differential genes (including 1,084 up-regulated genes and 4,673 downregulated genes) were identified, compared $0 \mathrm{~h}$ sample with $6 \mathrm{~h}$ sample comparisons identified total differential genes 14,200 (1,392 up-regulated genes, 12,808 down-regulated genes), compared $0 \mathrm{~h}$ sample with $9 \mathrm{~h}$ sample comparisons identified total differential genes 13,235 (1,419 up-regulated genes, 11,816 down-regulated genes), compared $0 \mathrm{~h}$ sample with $12 \mathrm{~h}$ sample comparisons identified total differential genes 15,876 (1,540 up-regulated genes, 14,336 down-regulated genes) (Fig. $3 A$ )(q values $\leq 0.001$, the 
gene abundance is 10.) a total of 4,400 genes were regulated simultaneously by MeJA at 0, 3, 6, 9 and 12 h, including 574 up-regulated and 3,826 down-regulated DEGs (Fig. 3B,C).

\subsection{GO and KEGG pathway enrichment analysis}

In order to understand the gene regulation mechanism of MeJA on GRA and SF anabolic pathways in broccoli hairy roots, $\mathrm{GO}$ enrichment analysis was performed on all screened up-regulated and downregulated DEGs in four groups ( $0 \mathrm{~h}$ and $3 \mathrm{~h}, 0 \mathrm{~h}$ and $6 \mathrm{~h}, 0 \mathrm{~h}$ and $9 \mathrm{~h}, 0 \mathrm{~h}$ and $12 \mathrm{~h}$ ). As shown in Fig. 4, raised and lowered DEGs from "Cellular components" "Molecular function" and "Biological process" three functional groups were identified 36 and 47 classifications. Up-regulated and down-regulated DEGs enriched common 6 categories in the "Molecular Function" functional group, but the order was different. Up-regulated and down-regulated DEGs in the process of "biological" functional groups were enriched in 18 and 23 categories, in addition to order difference, more down-regulated DEGs enriched in negative regulation of the process of "negative regulation of biological process", "biological adhesion", "behavior", "cell killing" and "locomotion" five categories. However, there were significant differences in the enrichment of up-regulated and down-regulated DEGs in the functional group of "cell component", and two more classifications were enriched in the down-regulated DEGs than the up-regulated DEGs, which indicated that exogenous MeJA had a greater effect on the "biological process" and "cell component" group.

At the same time, KEGG enrichment analysis was carried out on the up-regulated and down regulated DEGs selected from three groups ( $0 \mathrm{~h}$ and $3 \mathrm{~h}, 0 \mathrm{~h}$ and $6 \mathrm{~h}, 0 \mathrm{~h}$ and $9 \mathrm{~h}, 0 \mathrm{~h}$ and $12 \mathrm{~h}$ ). As shown in Fig. 5 , the top three in up-regulated enriched according to $\mathrm{P}$ value were "Alpha-Linolenic acid metabolism", "Glutathione metabolism" and "Sulfur metabolism". GLS is a sulfur-containing compounds (Kim et al., 2015), MeJA treatment hairy roots of broccoli promoted GLS metabolism. In addition, it is also enriched " endoplasmic reticulum protein processing". As a signaling molecule, MeJA required a large number of glycoproteins to transmit signals when it functioned in the hairy roots of broccoli. Galactose metabolism would produce a large amount of ATP (Lee et al., 2014), which would provide energy for the GRA biosynthesis in broccoli hairy roots and the conversion of GRA to SF. The increase of GRA production in broccoli hairy roots by MeJA may be due to the enhanced conversion of alanine to GRA, which needed further verification. The top three in down-regulated enrichment pathways of DEGs were "Phenylpropanoid biosynthesis", "Metabolic pathways" and "Biosynthesis of secondary metabolites", this indicated that the treatment of broccoli hairy roots with methyl jasmonate mainly affected the synthesis and metabolism of secondary metabolites.

\subsection{Analysis of DEGs in the biosynthesis of GRA}

To verify the results of RNA-Seq gene expression, qRT-PCR was used to detect the expression of 6 key genes and 3 key transcription factors in GLS synthesis of broccoli hairy roots after MeJA induction for 0,3,6,9 and 12 h. As shown in Fig. 6, the results of RNA-Seq and qRT-PCR matched well, which indicated the results of RNA-Seq were reliable. According to the results of transcriptome sequencing, 6 genes $($ FPKM $>10)$ were selected to regulate the biosynthesis of GLS in hairy roots of broccoli. BCAT2 and 
MAM1 played a major role in the process of side chain elongation, CYP79B1, CYP83B1 and UGT74B1 played a role in the process of core structure construction, and FMOGS-OX5 played a role in the process of side chain secondary modification. According to the Fig. 7, the GLS biosynthesis and transformation pathways containing key genes in hairy roots of broccoli was mapped in Fig. 8. As shown in Figs. 6, 7 and 8, the responses of BCAT2, MAM1, CYP79B1, CYP83B1, UGT74B1, FMOGS-OX5 and transcription factor MYB34, MYB51, MYB122 to MeJA were inconsistent. The six key genes that regulated GLS synthesis, MAM1, CYP79B1, UGT74B1, and FMOGS-OX5, were up-regulated at 0 and $3 \mathrm{~h}$, and downregulated at the rest of the time; $B C A T 2$ was up-CYP83B1 regulated at $6,9,12 \mathrm{~h}$, and at $0,3 \mathrm{~h}$ expression was down-regulated. Lee et al (2018) found that BCAT4 transcripts were observed in phloem, and the accumulation of BCAT4 transcripts followed a circadian rhythm. Subcellular protein localization showed that BCAT4 was localized in vacuole. The results explained the reason for the low expression of BCAT4 gene in GRA synthesis process in this study which was the weakening of phloem and vacuole function of hairy root in liquid suspension culture system resulted in BCAT4 gene expression was low. In addition, the expression of BCAT2 was high in this study, but BCAT3 and BCAT4 were more reported in the process elongation of GLS synthesis amino acid side chain in Brassica (Lee et al., 2018; Sonderby et al., 2010), while BCAT2 has not been reported. Wu et al (2017) found that the expression of GLS gene in 11 tissues of cabbage was higher than that of MAM1 gene in root tissue. Wu et al (2019) found that the treatment of cabbage with MeJA caused up-regulation of CYP79B1 and CYP83B1. However, Kong et al (2016) found that the expression of FMOGS-OX5 in Arabidopsis treated with MeJA was up-regulated compared with that in the control, which was different from this study. The reason may be that there was a difference in gene expression during the secondary side-chain modification of GLS in hairy root of broccoli, Because there are differences in the secondary modification of amino acid side chains, most Brassica plants were very conservative, but there were some differences in some Brassica plants (Sonderby et al., 2010). Comprehensive analyzing data of GRA and SF yield and RNA-Seq, it can be found that MeJA had a promoting effect on GRA and SF production in broccoli hairy roots. The possible reason was that, broccoli hairy roots had a response process to exogenous MeJA treatment in the early stage, and metabolites were accumulated in the later stage, which was similar with the research results that Guo et al (2013) find that jasmonates not only increased the content of indole group GLS in Arabidopsis, but also promoted the accumulation of aliphatic GLS. For the cause of the accumulation of aliphatic GLS in broccoli hairy roots treated by MeJA, it needs to be further explored. transcription factors MYB34 and MYB122 were up-regulated at $3 \mathrm{~h}$, and down-regulated at other time points, MYB51 was up-regulated at 0 , $3 \mathrm{~h}$, and down-regulated at 6, 9, $12 \mathrm{~h}$. Deng et al (2020) revealed the reason why exogenous addition of MeJA increased the yield of Salvia miltiorrhiza hairy root from the transcription factor level, which provided a research idea for MeJA-induced broccoli hairy roots to increase GRA and SF production. Jeon et al (2017) treated watercress with MeJA and found that there were differences in the expression of GLS biosynthesis key genes in different tissues. In addition, Wu et al (2017) found that GLS biosynthesis genes in cabbage were more strongly expressed in roots, petioles and aging leaves than in other tissues. This also explains the difference between the GLS synthesis genes of broccoli hairy roots and those of other cruciferous plants. 


\section{Declarations}

\section{Acknowledgments}

This work was financially supported by the fund of National Natural Science Foundation of China (31860067), Longyuan Youth Innovation and Entrepreneurship Project (2016-3-18), Gansu Provincial Department of education project (2017 a-035). Gansu science and technology project of people's livelihood(1603FCMG007).

\section{References}

1. Aghajanzadeh TA, Reich M, Kopriva S, Dekok LJ., 2018. Impact of chloride $(\mathrm{NaCl}, \mathrm{KCl})$ and sulphate $\left(\mathrm{Na}_{2} \mathrm{SO}_{4}, \mathrm{~K}_{2} \mathrm{SO}_{4}\right)$ salinity on glucosinolate metabolism in Brassica rapa[J]. Journal of Agronomy and Crop Science, 204:137-146. https://doi.org/10.1111/jac.12243

2. Baenas N, Viguera CC, Moreno DA., 2014. Biotic elicitors effectively increase the glucosinolates Content in brassicaceae Sprouts. Journal of Agricultural \&Food Chemistry, 62:18811889._https://doi.org/10.1021/jf404876z

3. Banerjee A, Rai AN, Penna S, Variyara PS., 2016. Aliphatic glucosinolate synthesis and gene expression changes in gamma-irradiated cabbage. Food Chemistry, 209:99103. https://doi.org/10.1016/j.foodchem.2016.04.022

4. Cacho M, Paleaz R, Corchete P., 2012. Lipid composition of Silybum marianumcell cultures treated with methyl jasmonate. Biologia Plantarum, 56:221-226. https://doi.org/10.1007/s10535-012-0080-8

5. Choi WJ, Kim SK, Park HK, Sohn DU, Kim WY., 2014. Anti-Inflammatory and anti-superbacterial properties of sulforaphane from shepherd's purse. Korean Journal OF Physiology \& Pharmacology Official Journal OF The Korean Physiological Society \& The Korean Society of Pharmacology, 18:3339. https://doi.org/10.4196/kjpp.2014.18.1.33

6. Deng C, Wang Y, Huang F, et al., 2020. SmMYB2 promotes salvianolic acid biosynthesis in the medicinal herb Salvia miltiorrhiza. Journal of Integrative Plant Biology, Online on: Apr. 28, 2020. https://doi.org/10.1111/jipb.12943

7. Guo RF, Shen WS, Qian HM, Zhang M, Liu LH, Wang QM., 2013. Jasmonic acid and glucose synergistically modulate the accumulation of glucosinolates in Arabidopsis thaliana. Journal of Experimental Botany, 64:5707-5719. https://doi.org/10.1093/jxb/ert348

8. Hu CZ., 2016. Establishment of hairy root amplification system of broccoli and regulation of sulfur accumulation of radish by fungal elicitors. Lanzhou: Gansu Agricultural University.http://kns.cnki.net/kns/detail/detail.aspx?

FileName $=1016902812$. nh\&DbName $=$ CMFD2017

9. Jeon J, Bong SJ, Park JS, Park YK, Arasu MV, Al-Dhabi NA, Park SU., 2017. De novo transcriptome analysis and glucosinolate profiling in watercress (Nasturtium officinale R. Br.). BMC Genomics, 401:1-14._https://doi.org/10.1186/s12864-017-3792-5 
10. Jiao J, Gai QY, Wang W, Zang YP, Niu LL, Fu YJ, Wang X., 2018. Remarkable enhancement of flavonoid production in a co-cultivation system of Isatis tinctoria L. hairy root cultures and immobilized Aspergillus niger. Industrial Crops and Products, 112:252261. https://doi.org/10.1016/j.indcrop.2019.05.083

11. Kang K, Yu MZ., 2017. Protective effect of sulforaphane against retinal degeneration in the Pde $6^{\text {rd10 }}$ mouse model of retinitis pigmentosa. Current Eye Research, 42:16841688._https://doi.org/10.1080/02713683.2017.1358371

12. Klaus PL, Klaus EA, Alfonso L., 2011. Health benefits and possible risks of broccoli-An overview. Food and Chemical Toxicology, 49:3300-3309. https://doi.org/10.1016/j.fct.2011.08.019

13. Kim D, Pertea G, Trapnell C, Pimentel H, Kelley R, Salzberg SL., 2013. TopHat2: accurate alignment of transcriptomes in the presence of insertions, deletions and gene fusions. Genome Biology, 14:113. https://doi.org/10.1186/gb-2013-14-4-r36

14. Kim J I, Dolan W L, Anderson N A, et al. Indole Glucosinolate Biosynthesis Limits Phenylpropanoid Accumulation in Arabidopsis thaliana. [J]. Plant Cell, 2015, 27(5):1529-

1546. https://doi.org/10.1105/tpc. 15.00127

15. Kim MJ, Chiu YC, Kim NK, Park HM, Lee CH, Juvik JA, Ku KM., 2017. Cultivar-specific changes in primary and secondary metabolites in Pak Choi (Brassica Rapa, Chinensis Group) by Methyl Jasmonate. International Journal of Molecular Sciences, 18:1-

17. https://doi.org/10.3390/ijms18051004

16. Kong WW, Li J, Yu QY, Cang W, Xu R, Wang Y, Ji W., 2016. Two novel flavin-containing monooxygenases involved in biosynthesis of Aliphatic glucosinolates. Frontiers in Plant Science, 7:19. https://doi.org/10.3389/fpls.2016.01202

17. Langmead B, Salzberg S L., 2012. Fast gapped-read alignment with Bowtie 2. Nature Methods, 9:357359._https://doi.org/10.1038/NMETH.1923

18. Lee MJ, Gravelat FN, Cerone RP, Baptista SD, Campoli PV, Choe SI,Kravtsov I, Vinogradov E, Creuzenet C, Liu H, Berghuis AM, Latgé JP, Filler SG, Fontaine, Donald C.,2014. Overlapping and distinct roles of Aspergillus fumigatus UDP-glucose 4-Epimerases in galactose metabolism and the synthesis of galactose-containing cell wall polysaccharides. Journal of Biological Chemistry, 289:12431256._https://doi.org/10.1074/jbc.M113.522516

19. Lee JH, Lee JY, Kim HR, Chae WB, Kim SJ, Lim YP, HoOh M. Brassinosteroids regulate glucosinolate biosynthesis in Arabidopsis thaliana[J]. Physiologia plantarum, 2018,163(4):1-13.

20. https://doi.org/10.1111/ppl.12691

21. Luo Y, Li F, Wang GP, et al., 2010. Exogenously-supplied trehalose protects thylakoid membranes of winter wheat from heat-induced damage. Biologia Plantarum, 55: 495-

501. https://doi.org/10.1007/s10535-010-0087-y

22. Makoto S, Ikuko HN, 2018. Specialized vacuoles of myrosin cells: chemical defense strategy in brassicales plants. Plant and Cell Physiology, 59:1309-1316. https://doi.org/10.1093/pcp/pcy082 
23. Miao HY, Cai CX, Wei J, Huang JR, Chang JQ, Qian HM, Zhang X, Zhao YT, Sun B, Wang BL, Wang QM., 2016. Glucose enhances indolic glucosinolate biosynthesis without reducing primary sulfur assimilation. Scientific Reports, 6:1-12. https://doi.org/10.1038/srep31854

24. SanchezPujante PJ, Martınez MB, Pedreno MA, Almagro A., 2017. Biosynthesis and bioactivity of glucosinolates and their production in plant in vitro cultures. Planta, 246:1-

14. https://doi.org/10.1007/s00425-017-2705-9

25. Shilpha J, Satish L, Kavikkuil M, Largir M, Ramesh M., 2015. Methyl jasmonate elicits the solasodine production and anti-oxidant activity in hairy root cultures of Solanum trilobatum L. Industrial Crops and Products, 71:54-64. https://doi.org/10.1016/j.indcrop.2015.03.083

26. Siwach P, Gill AR, Sethi K., 2013. Hairy Root cultures of medicinal trees: A viable alternative for commercial production of high-Value secondary metabolites. Biotechnology: Prospects and Applications. https://doi.org/10.1007\%2F978-81-322-1683-4

27. Sønderby IE, Flores FG, Halkier BA., 2010. Biosynthesis of glucosinolates gene discovery and beyond. Trends in Plant Science, 15:283-290. https://doi.org/10.1016/j.tplants.2010.02.005

28. Tang L, Paonessa JD, Zhang YS, Ambrosone CB, McCann SE., 2013. Total isothiocyanate yield from raw cruciferous vegetables commonly consumed in the United States. Journal of Functional Foods, 5:1996-2001. https://doi.org/10.1016/j.jff.2013.07.011

29. Traka MH., 2016. Health benefits of glucosinolates. Advances in Botanical Research, 6:247269. https://doi.org/10.1016/bs.abr.2016.06.004

30. Trapnell C, Roberts A, Goff L, Pertea G, Kim D, Kelley DR, Pimentel H, Salzberg SL, Rinn JL, Pachter L., 2012. Differential gene and transcript expression analysis of RNA-seq experiments with TopHat and Cufflinks. Nature Protocols, 7:562-578. https://doi.org/10.1038/nprot.2012.016

31. Trapnell C, Williams B A, Pertea G, Mortazavi A, Kwan G, Bweren MJ, Salzberg SL Wold BJ, Pachter L., 2010. Transcript assembly and quantification by RNA-Seq reveals unannotated transcripts and isoform switching during cell differentiation. Nature Biotechnology, 28:511-

515. https://doi.org/10.1186/gb-2013-14-4-r36

32. Vo QV, Rochfort S, Nam PC, Nguyen TL, Nguyen TT, Mechl A., 2018. Synthesis of aromatic and indole alpha-glucosinolates. Carbohydrate Research, 455:45-

53. https://doi.org/10.1016/j.carres.2017.11.004

33. Wang QJ, Zheng LP, Yuan HY Wang JW., 2013. Propagation of Salvia miltiorrhiza from hairy root explants via somatic embryogenesis and tanshinone content in obtained plants. Industrial Crops and Products, 50:648-653. https://doi.org/10.1016/j.indcrop.2013.08.031

34. Wu QY, Wang JW, Mao SX, Xu HR, Wu Q, Liang MT, Yuan YM, Liu MY, Huang K., 2019. Comparative transcriptome analyses of genes involved in sulforaphane metabolism at different treatment in Chinese kale using full-length transcriptome sequencing. BMC Genomics, 20:1-

13. https://doi.org/10.1186/s12864-019-5758-2

35. Wu SH, Lei JJ, Chen GJ, Chen HC, Cao BH, Chen CM., 2017. De novo Transcriptome assembly of Chinese Kale and global expression analysis of genes involved in glucosinolate metabolism in 
multiple tissues. Frontiers in Plant Science, 8:1-16. https://doi.org/10.3389/fpls.2017.00092

36. Yu QY, Hao GD, Zhou JX, Wang JY, Evivie ER, Li J., 2018. Identification and expression pattern analysis of BOMYB51 involved in indolic glucosinolate biosynthesis from broccoli (Brassica oleracea var. italica). Biochemical \& Biophysical Research Communications, 501:598-

604._https://doi.org/10.1016/j.bbrc.2018.05.058

37. Zang YX, Zhang H, Huang LH, Wang F, Gao F, Lv XS, Yang J, Zhu B, Hong SB, Zhu ZJ.,2016. Glucosinolate enhancement in leaves and roots of pak choi (Brassica rapa ssp. chinensis) by Methyl Jasmonate. Asian Horticultural Congress, 56:830-840._https://doi.org/10.1007/s13580-015-0079-0

38. Zhang CC, Ma SY, Li S, Yu Y, Zhang XM, Bao JY., 2020 Establishment of suspension culture system for hairy roots of broccoli [J]. Molecular plant breeding, 18 (04): 1250-

1258.http://kns.cnki.net/kcms/detail/detail.aspx?

FileName=FZZW202004032\&DbName=DKFX2020

39. Zhang JF, Liu ZY, Liang JL, Wu J, Cheng F, Wang XW., 2015. Three genes encoding AOP2 a protein involved in aliphatic glucosinolate biosynthesis, were differentially expressed in Brassica rapa. Journal of Experimental Botany, 66:6205-6218. https://doi.org/10.1093/jxb/erv331

40. Zhao SQ., 2015. Induction of hairy roots of broccoli and establishment of multiplication system. Gansu Agricultural University. http://kns.cnki.net/kns/detail/detail.aspx?

FileName $=1015975361$. nh\&DbName $=$ CMFD2016

41. Zhao L, Wang C, Zhu F, Li Y., 2017. Mild osmotic stress promotes 4-methoxy indolyl-3-methyl glucosinolate biosynthesis mediated by the MKK9-MPK3/MPK6 cascade in Arabidopsis. Plant Cell Reports, 36:543-555. https://doi.org/10.1007/s00299-017-2101-8

\section{Tables}


Table 1: primer sequences used in qRT-PCR analysis

\begin{tabular}{|c|c|c|}
\hline Genename & Primersequenes(5'to3') & Accession \\
\hline \multirow[t]{2}{*}{$A C T$} & Forward:TGATTGTGGAGAAACTCGGTG & XM013769929.1 \\
\hline & Reverse:GGTGCGGCTCTTGAAAACATC & \\
\hline \multirow[t]{2}{*}{$B C A T 2$} & Forward:GCAAGAGGAGCGTAAGAAACC & XM013731889.1 \\
\hline & Reverse:GCAGGTGCTAAACCAAGAACT & \\
\hline \multirow[t]{2}{*}{$M A M I$} & Forward:GTGCTGTGGGGATGGTTGTT & XM013780555.1 \\
\hline & Reverse:GCCTTTGACCCGTATCGTTTCT & \\
\hline \multirow[t]{2}{*}{$C Y P 79 B 1$} & Forward:CGGGAAAAGAGGTTGTGCTG & XM013738169.1 \\
\hline & Reverse:CGTCGGGTAAAGATGCTCC & \\
\hline \multirow[t]{2}{*}{ CYP83BI } & Forward:GCAAGTTTCCGACCCGTTAG & XM013749594.1 \\
\hline & Reverse:CCGTCTCAGGTTTAGGGCG & \\
\hline \multirow[t]{2}{*}{$U G T 74 B 1$} & Forward:TGAGTTTCCTCTCCCCGCT & XM013730524.1 \\
\hline & Reverse:CAGCCAATCAGCATCTTCGTG & \\
\hline \multirow[t]{2}{*}{ FMOGS-OX5 } & Forward:ATGATGGAGGACACTAACGCC & XM013749606.1 \\
\hline & Reverse:CCGACGACACCAAGACGATG & \\
\hline \multirow[t]{2}{*}{ MYB34 } & Forward:TTTGGCGGGACGAACAGACAAC & XM013740125.1 \\
\hline & Reverse:ATCGGTTTGTGAGTGGTTGGATCG & \\
\hline \multirow[t]{2}{*}{ MYB51 } & Forward:GACACCGTGTTGCAAAGCTGAAC & $\mathrm{XM} 013749453.1$ \\
\hline & Reverse:GAGAGTTCGCCATCCACCTTCAC & \\
\hline \multirow[t]{2}{*}{ MYB122 } & Forward:CGTGTTGCAGAGCGGAAGGG & XM013735007.1 \\
\hline & Reverse:GTGAAGTTGGACGTAGGCGATGAG & \\
\hline
\end{tabular}


Table 2: MeJA induce sequencing data and quality statistics of 15 transcriptome data from broccoli hairy roots at 5 time points

\begin{tabular}{rrrrrrrr}
\hline Samples & $\begin{array}{r}\text { No. of raw } \\
\text { reads }\left(10^{6}\right)\end{array}$ & $\begin{array}{c}\text { No. of clean } \\
\text { reads }\left(10^{6}\right)\end{array}$ & $\begin{array}{c}\text { No. of base } \\
\text { pairs }\left(10^{9}\right)\end{array}$ & $\begin{array}{c}\text { GC content } \\
(\%)\end{array}$ & $\begin{array}{c}\text { Q30 (\%) } \\
\text { Total Mapped }\end{array}$ & $\begin{array}{c}\text { TotalMapped } \\
\text { reads (10 })\end{array}$ & percentage(\%) \\
\hline T0-1 & 53.61 & 53.52 & 8.04 & 47.71 & 94.57 & 47.04 & 90.86 \\
T0-2 & 48.43 & 48.36 & 7.26 & 47.70 & 94.46 & 42.50 & 90.90 \\
T0-3 & 53.52 & 53.43 & 8.03 & 47.53 & 95.01 & 46.98 & 90.92 \\
T3-1 & 59.81 & 59.74 & 8.97 & 47.59 & 94.97 & 53.41 & 91.95 \\
T3-2 & 42.14 & 42.08 & 6.32 & 47.58 & 94.92 & 37.13 & 91.64 \\
T3-3 & 45.16 & 45.08 & 6.77 & 47.47 & 95.01 & 39.91 & 91.74 \\
T6-1 & 51.54 & 51.47 & 7.73 & 47.42 & 95.06 & 45.99 & 91.14 \\
T6-2 & 41.08 & 41.02 & 6.16 & 47.42 & 95.22 & 36.79 & 91.34 \\
T6-3 & 42.67 & 42.62 & 6.40 & 47.70 & 95.58 & 37.19 & 91.11 \\
T9-1 & 63.08 & 63.01 & 9.46 & 47.61 & 96.65 & 55.52 & 91.09 \\
T9-2 & 48.38 & 48.32 & 7.26 & 47.61 & 95.60 & 42.77 & 91.28 \\
T9-3 & 49.20 & 49.16 & 7.38 & 48.12 & 95.93 & 43.86 & 91.61 \\
T12-1 & 60.09 & 60.02 & 9.01 & 47.50 & 95.55 & 52.32 & 90.34 \\
T12-2 & 46.19 & 46.14 & 6.93 & 47.55 & 95.58 & 43.86 & 90.31 \\
T12-3 & 39.36 & 39.32 & 5.90 & 47.63 & 95.62 & 52.32 & 90.33 \\
\hline
\end{tabular}

Raw reads: total number of bases in offline data (unit: BP); clean reads: the number of clean reads, the single-ended meter; clean bases: the number of clean data; GC content: the percentage of GCcontent in clean data; $\mathbf{Q 3 0} \%$ : Q-score of clean data $\geq 30$; Total mapped reads: the number of reads mapped to the reference genome and its percentage in clean reads.

\section{Figures}



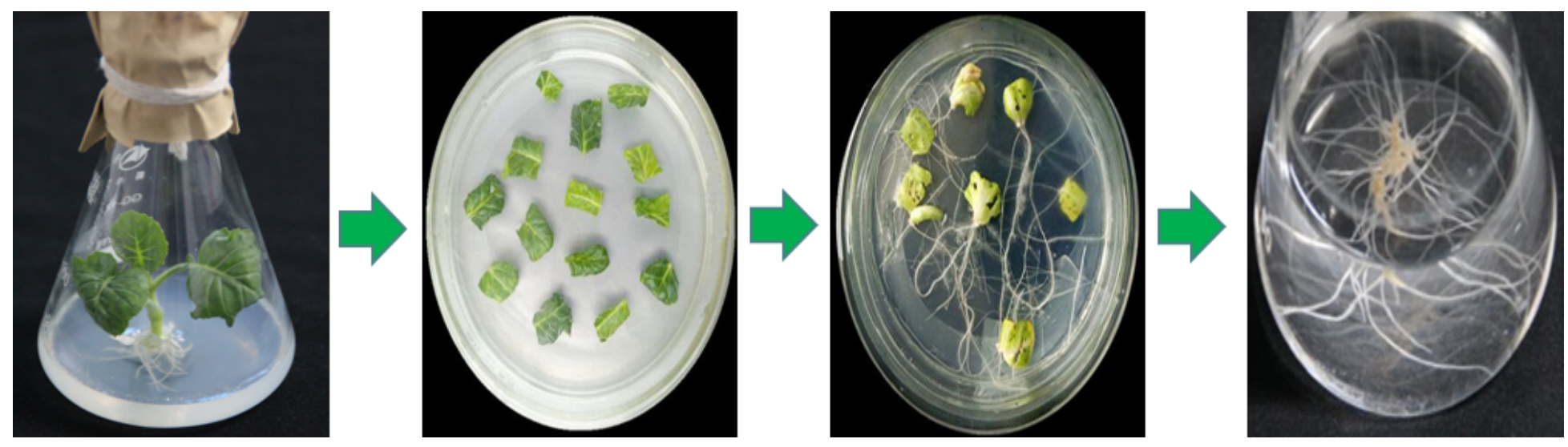

Figure 1

Development of broccoli hairy root cultures

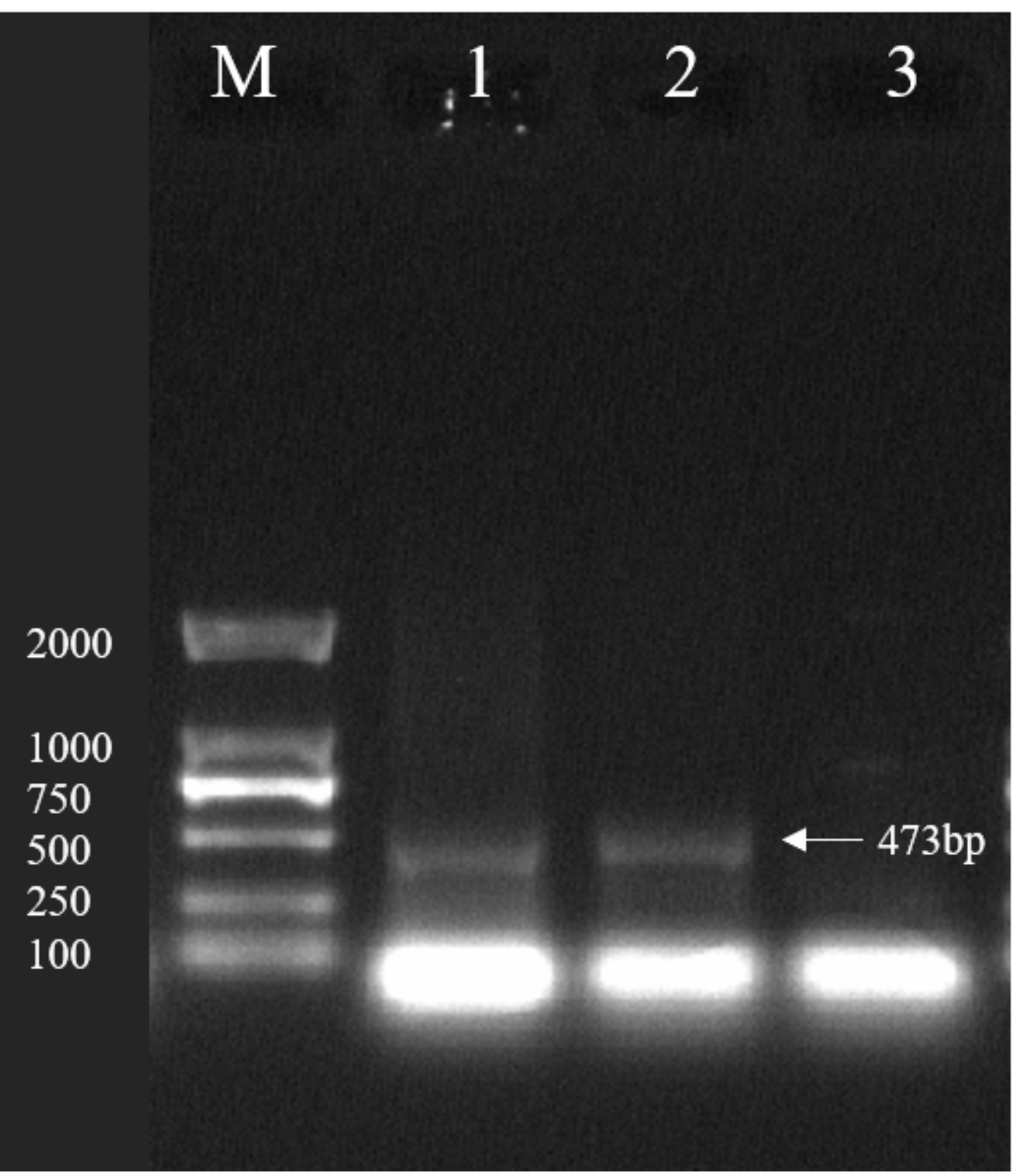

Figure 2 
Results of rolC electrophoresis M: mark D2000; 1: Plasmid DNA; 2: Hairy Roots of broccoli genomic DNA; 3: Aseptic seedling of broccoli genomic DNA
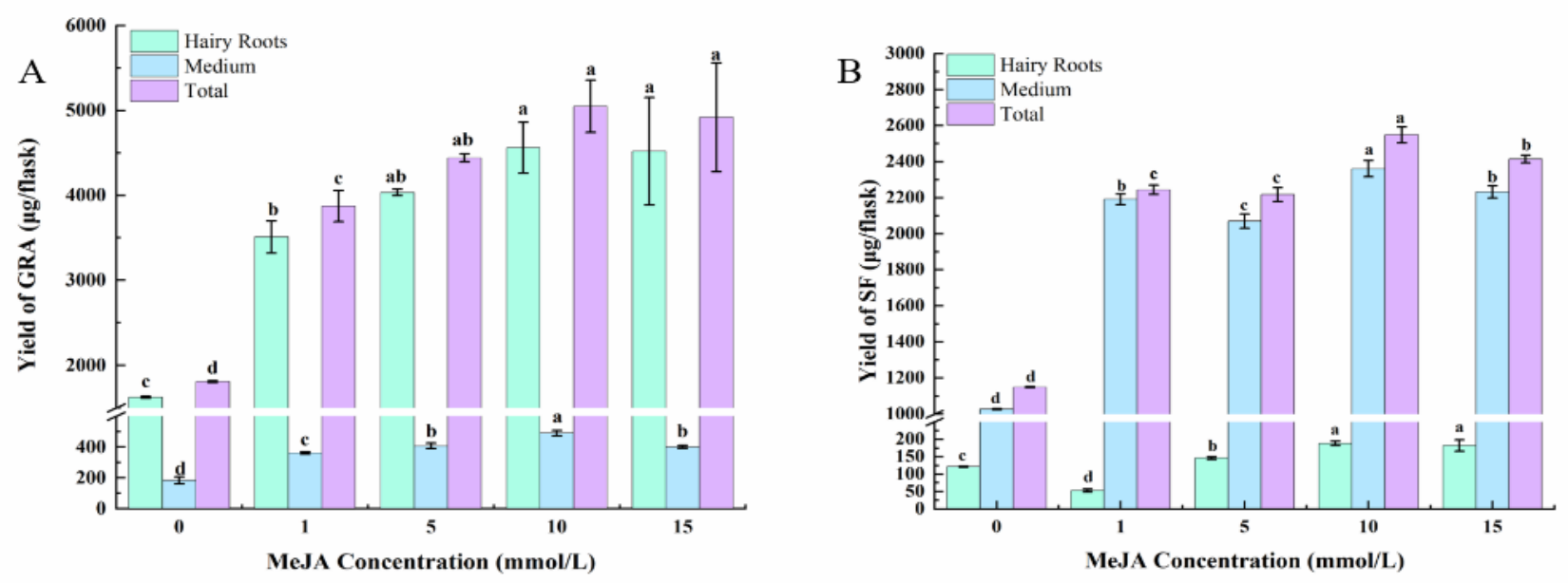

\section{Figure 3}

Effects of MeJA treatment of different concentrations on GRA and SF yield (A) GRA yield of broccoli hairy roots treated with $0,1,5,10$ and $15 \mathrm{mmol} / \mathrm{L} \mathrm{MeJA}$ for $12 \mathrm{~h}$, (B) SF yield of broccoli hairy roots treated with $0,1,5,10$ and $15 \mathrm{mmol} / \mathrm{L}$ MeJA for $12 \mathrm{~h}$ Notes: There was a significant difference between different lowercase letters on the same polyline in the picture $(P \leq 0.05)$
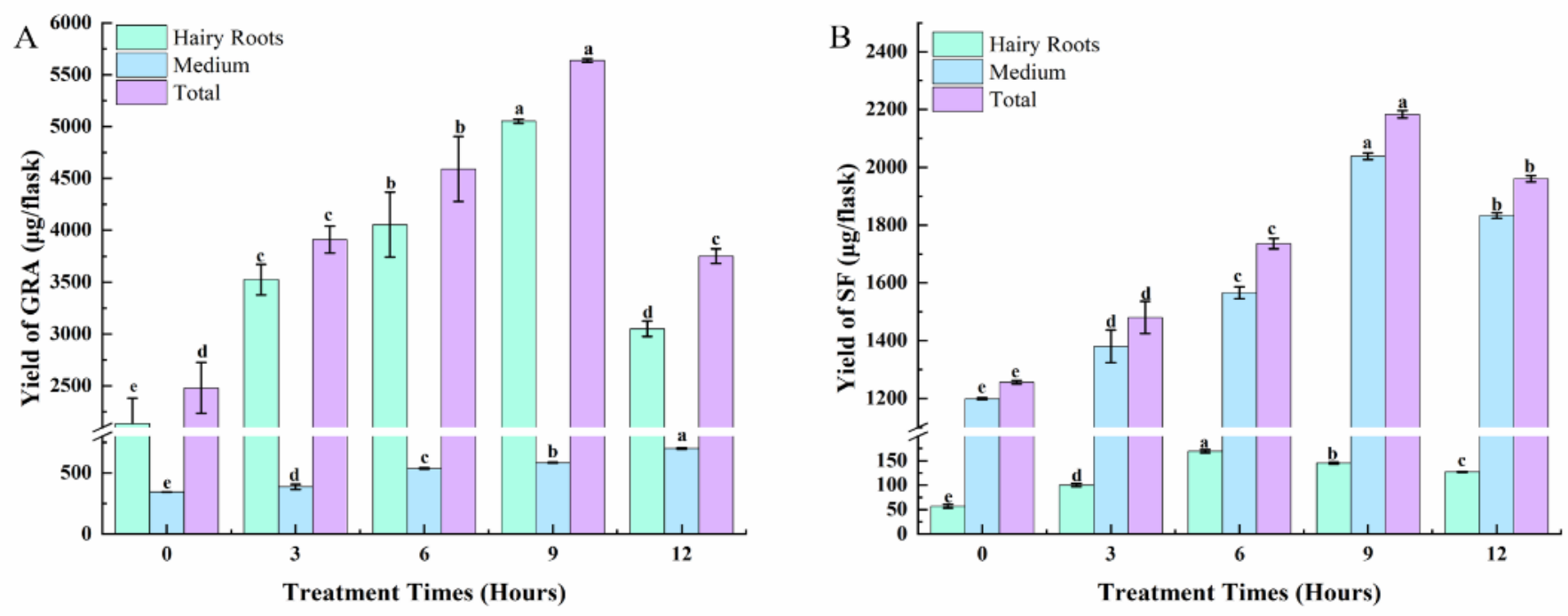

Figure 4

Effect of MeJA treatment at different time on yield of GRA and SF in broccoli hairy roots (A) GRA yield of broccoli hairy roots treated with $10 \mathrm{mmol} / \mathrm{L}$ MeJA for $0,3,6,9$ and 12 hours, (B) SF yield of broccoli hairy roots treated with $10 \mathrm{mmol} / \mathrm{L}$ MeJA for $0,3,6,9$ and 12 hours. Notes $\bigotimes T$ There was a significant difference between different lowercase letters on the same polyline in the picture $(P \leq 0.05)$ 


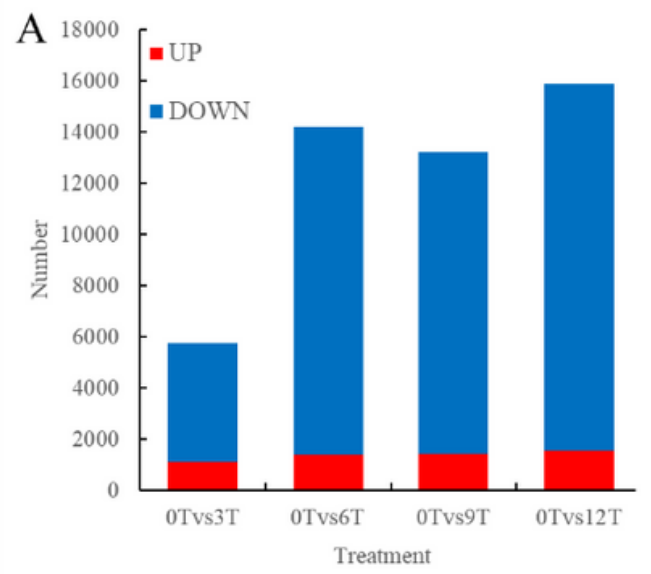

B

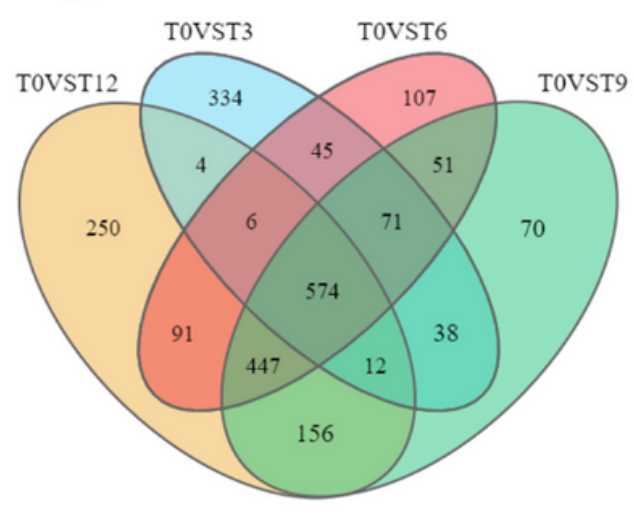

$\mathrm{C}$

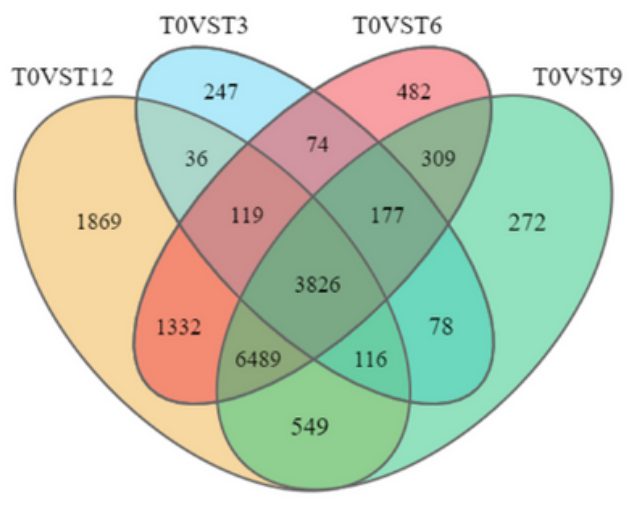

\section{Figure 5}

Distribution of differentially expressed genes (DEGs) in hairy roots of broccoli treated with MeJA for 0,3 , 6,9 and $12 \mathrm{~h}$ (A) Column diagram representing the numbers of DEGs in four groups. (B) Venn diagrams representing the numbers of DEGs and the overlaps of sets obtained across four comparisons. 

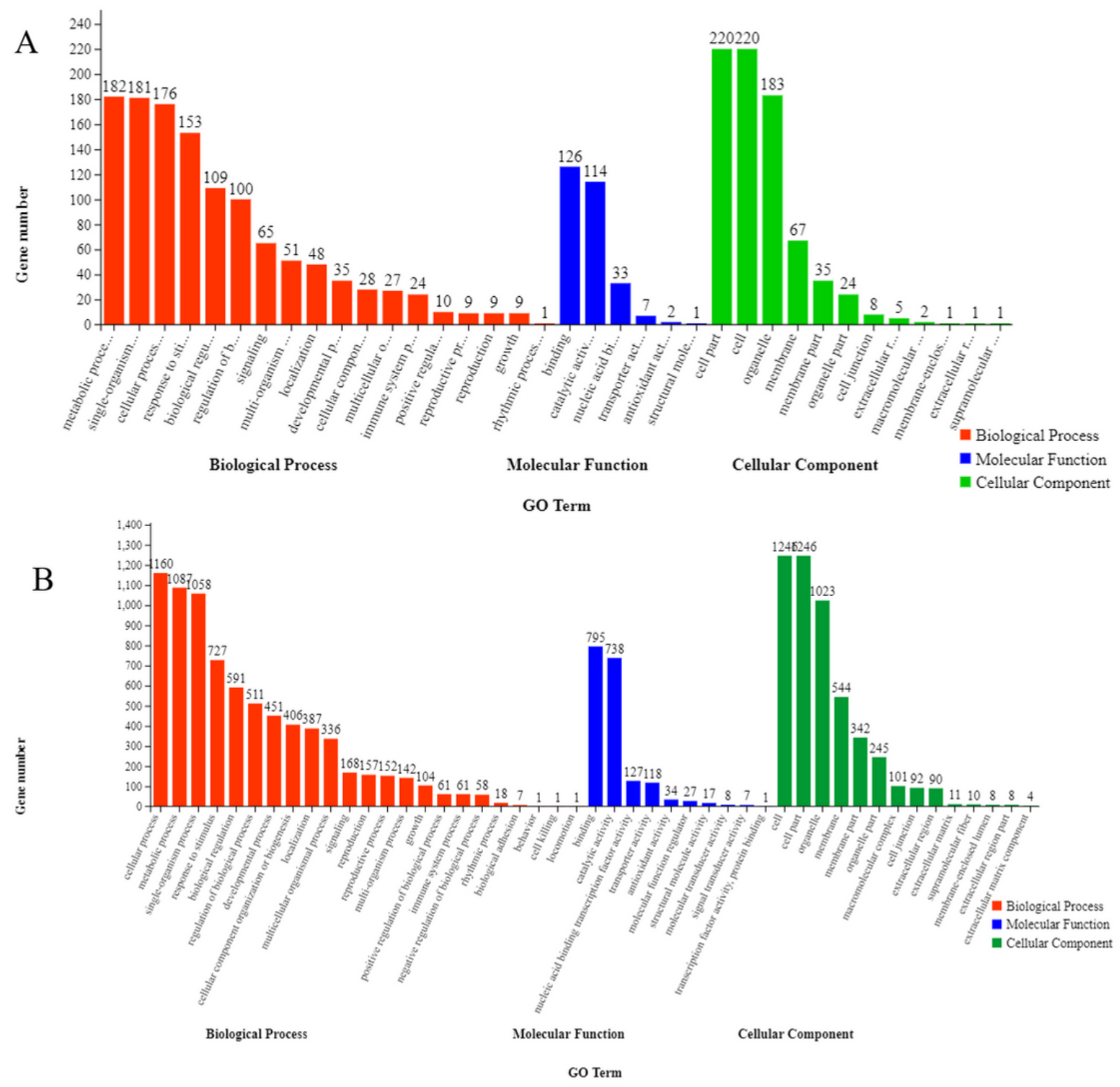

Figure 6

The GO annotation functional annotation of differentially expressed genes (DEGs) in hairy roots of broccoli treated by MeJA for 0, 3, 6, 9 and $12 \mathrm{~h}(\mathrm{~A})$ MeJA treatment of broccoli hairy roots at 0,3,6,9 and $12 \mathrm{~h}$ common up-regulated DEGs. (B) MeJA treatment of broccoli hairy roots at $0,3,6,9$ and $12 \mathrm{~h}$ common down-regulated DEGs. 

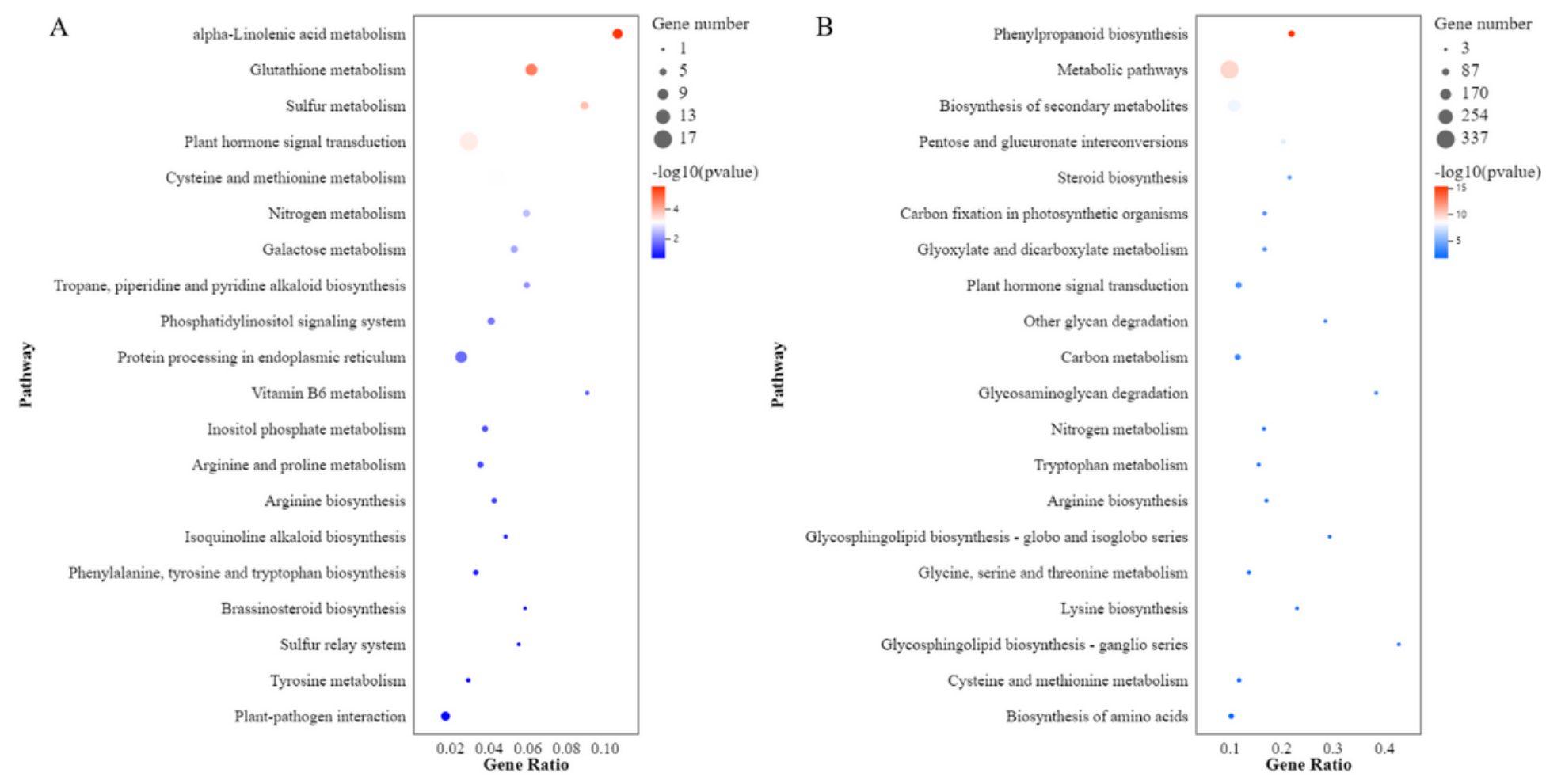

\section{Figure 7}

The KEGG pathway functional annotation of differentially expressed genes (DEGs) in hairy roots of broccoli treated by MeJA for 0, 3, 6, 9 and $12 \mathrm{~h}$ (A) MeJA treatment for 0, 3, 6, 9 and $12 \mathrm{~h}$ showed the top 20 pathways of common up-regulated DEGs enrichment annotation. (B) MeJA treatment for $0,3,6,9$ and $12 \mathrm{~h}$ showed the top 20 pathways of common down-regulated DEGs enrichment annotation. The size and color of the solid circles represent the number of genes involved in the specific pathway and the enriched Q-value (Q-value) of the metabolic pathway, respectively 

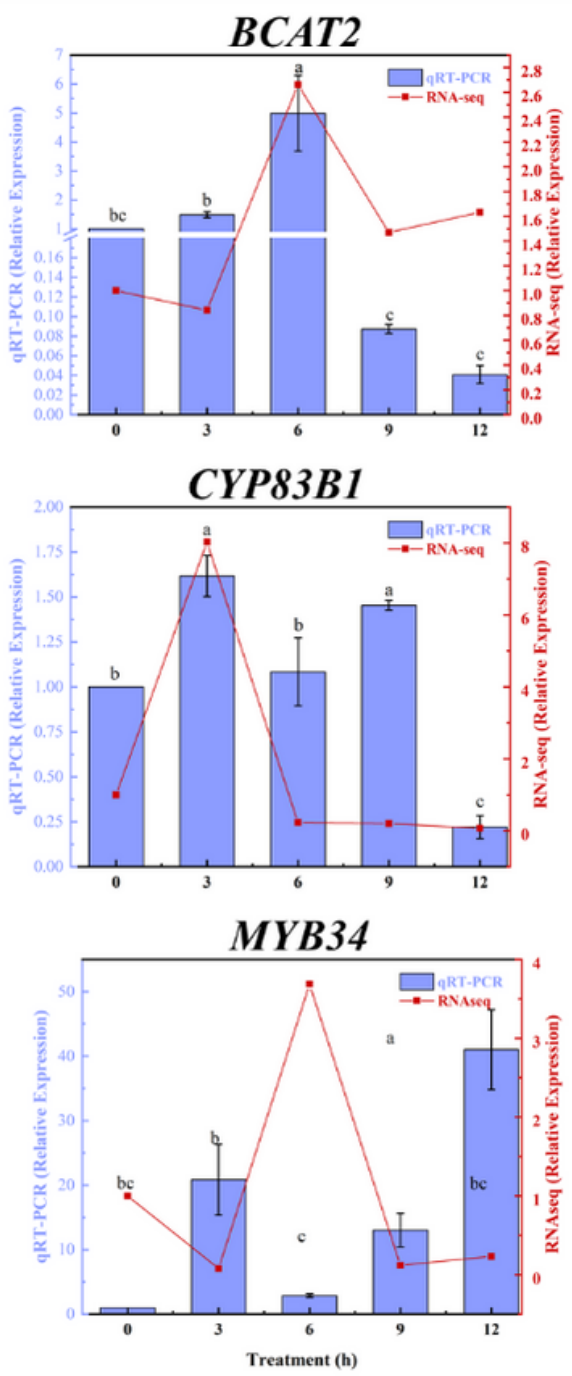

MAM1

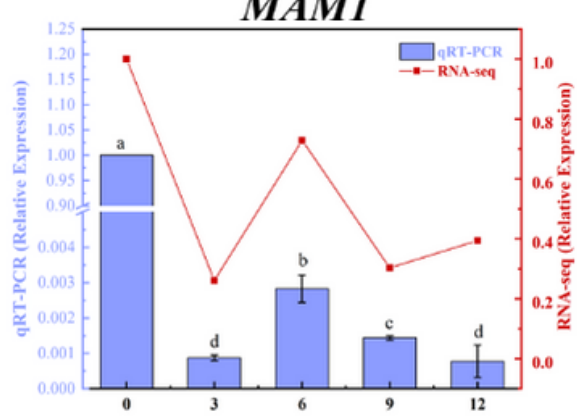

UGT74B1

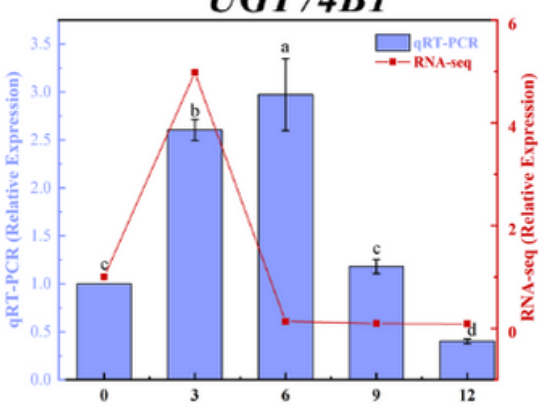

MYB51

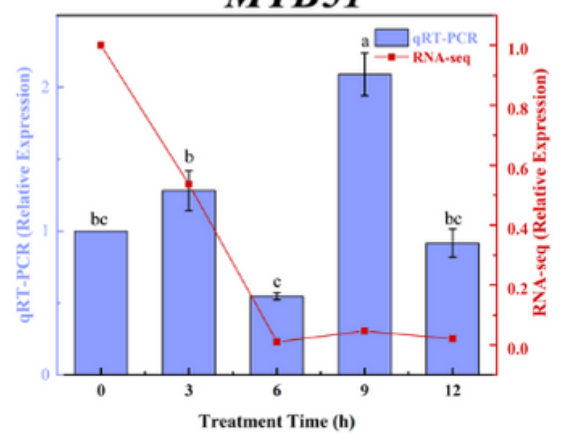

CYP79B1

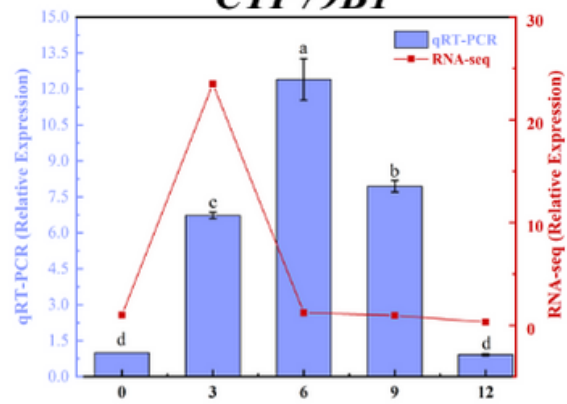

FMOGS-OX5

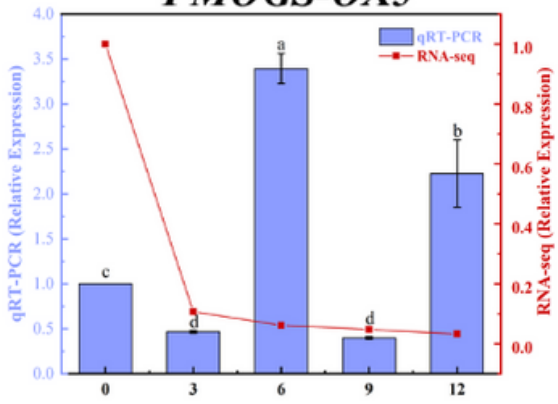

MYB122

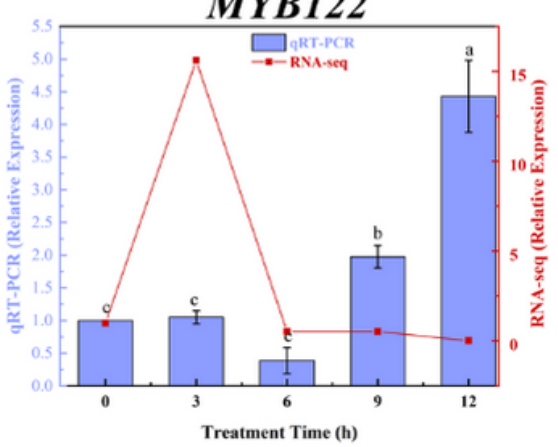

Figure 8

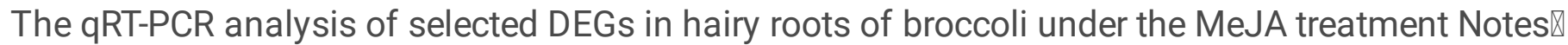
Different small letters in the figure showed significant difference $(P \leq 0.05)$ 


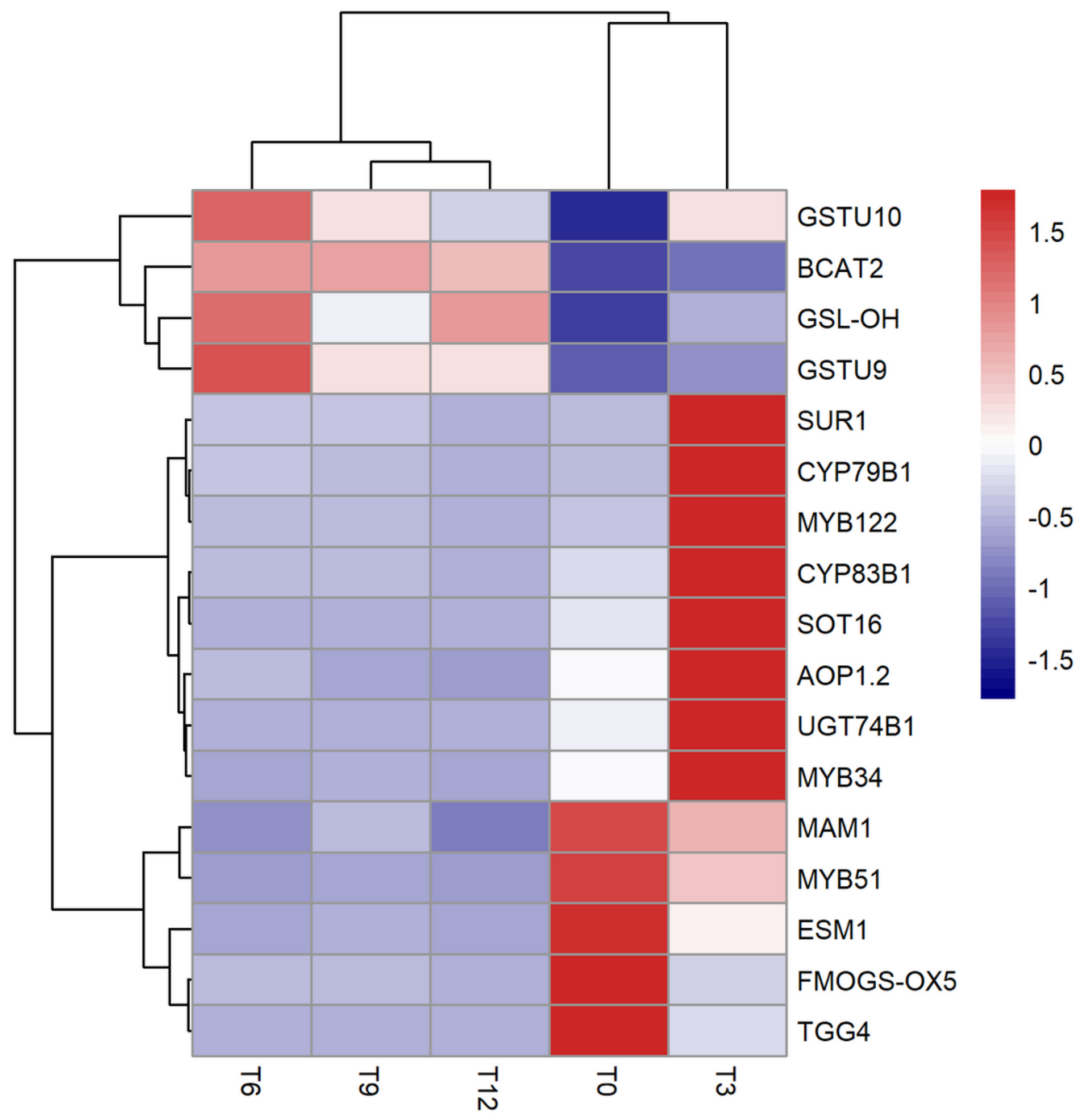

Figure 9

Cluster analysis heat map of DEGs in GLS synthesis pathway after MeJA treatment hairy roots of broccoli for $0,3,6,9,12 \mathrm{~h}$ 


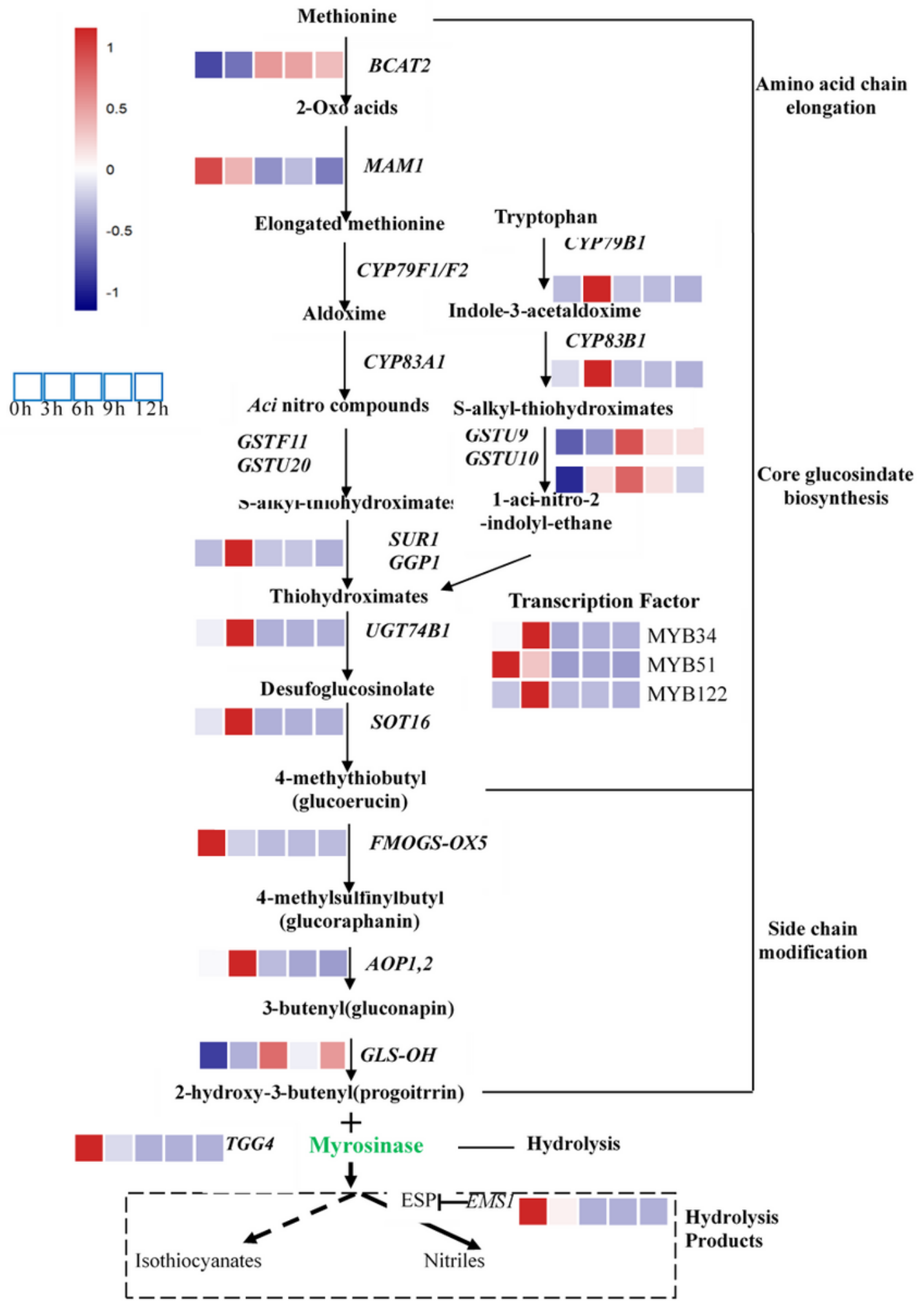

Figure 10

Expression of key DEGs in the biosynthesis and transformation pathway of GRA in different groups of samples (refer to Wu et al., 2017) Black: in this study, RNA-Seq obtained a relatively high expression of gene.Blue: GLS synthesis pathway classic gene 